\title{
Study on morphological properties of barium titanate: titanium dioxide : PMMA composite films
}

\author{
Sudhanshu Singh ${ }^{1 *}$, Subhrangu S Dey ${ }^{2}$, Sheshamani Singh ${ }^{2}$ and Neeraj Kumar ${ }^{2}$ \\ ${ }^{1}$ Amity School of Engineering and Technology, Amity University Rajasthan, Jaipur-303002, India \\ ${ }^{2}$ Amity School of Applied Sciences, Amity University Rajasthan, Jaipur-303002, India \\ *Email: ssingh3@jpr.amity.edu
}

In this paper, we have developed composite films of Barium Titanate $\left(\mathrm{BaTiO}_{3}\right)$ and Poly (methyl methacrylate) prepared by solution casting technique.[1,2] Different weight percentage composition of $\mathrm{BaTiO}_{3}$ have been selected to find out the best optimization condition for further investigation and correlate their results. The structural properties have been carried out at room temperature using XRD. The average crystallite size of the $\mathrm{BaTiO}_{3}$ particles in the composite films has been found to be lies in between $\sim 20-30 \mathrm{~nm}$ It has been found that the peak intensities increases with increasing the wt. $\%$ of $\mathrm{BaTiO}_{3}$ in the composite films. The XRD analysis revealed that the addition of $\mathrm{TiO}_{2}$ has played a crucial role to enhance the crystalline nature of the composite films at room temperature.[3] Efforts have been made to correlate the results with investigated XRD results of pure $\mathrm{BaTiO}_{3}$ and its composites as observed by other workers at room temperature. The flow of experimental work and microscopic images are given in Figure 1 and Figure 2 respectively.

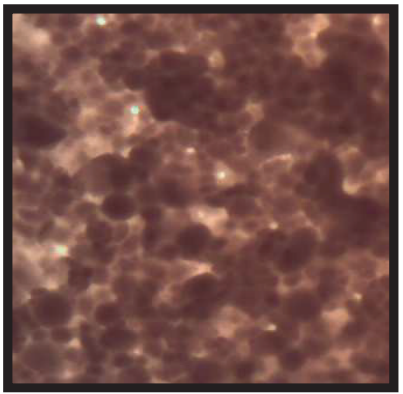

Figure 2: Microscopic image of composite (10X)

Keywords: $\quad \mathrm{BaTiO}_{3}$, Poly (methyl methacrylate), Solvent caste, $\mathrm{TiO}_{2}, \mathrm{XRD}$.

\section{References}

1. Neeraj Kumar and R. Nath, J. Appl. Phys. 97, 024105 (2005)

2. Z. Guo, S.-E. Lee, H. Kim, S.Park, H.T. Hahn, A.B. Karki and D.P. Young, Acta Materials, 57, 67277, (2009)

3. Ravindra H. Upadhyay and Rajendra R. Deshmukh, Advances in Materials Research,Vol. 2, No. 2, 99-109, (2013)

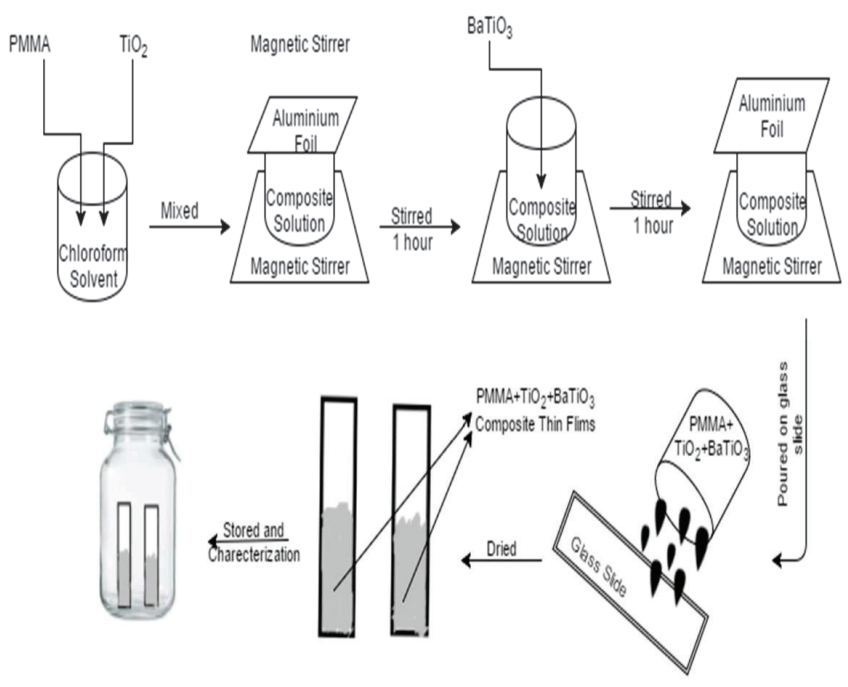

Figure 1: Experimental work 